Article

\title{
Green Stability Indicating Organic Solvent-Free HPLC Determination of Remdesivir in Substances and Pharmaceutical Dosage Forms
}

\author{
Adel Ehab Ibrahim ${ }^{1}$ (D), Sami El Deeb ${ }^{2,3, * \mathbb{D}}$, Emad Mahmoud Abdelhalim ${ }^{4}$, Ahmed Al-Harrasi ${ }^{3}(\mathbb{D}$ \\ and Rania Adel Sayed ${ }^{5}$ \\ 1 Analytical Chemistry Department, Faculty of Pharmacy, Port-Said University, Port Said 42526, Egypt; \\ pharmacist_adel_2005@yahoo.com \\ 2 Institute of Medicinal and Pharmaceutical Chemistry, Technische Universitaet Braunschweig, \\ 38106 Braunschweig, Germany \\ 3 Natural and Medical Sciences Research Center, University of Nizwa, P.O. Box 33, Birkat Al Mauz, \\ Nizwa 616, Oman; aharrasi@unizwa.edu.om \\ 4 Chemistry Department, Zagazig University, Zagazig 44519, Egypt; emadabdelhalim1979@yahoo.com \\ 5 Analytical Chemistry Department, Faculty of Pharmacy, Zagazig University, Zagazig 44519, Egypt; \\ raniaadelsayed@gmail.com \\ * Correspondence: s.eldeeb@tu-bs.de; Tel.: +49-531-391-7301
}

check for

updates

Citation: Ibrahim, A.E.; Deeb, S.E.; Abdelhalim, E.M.; Al-Harrasi, A.; Sayed, R.A. Green Stability Indicating Organic Solvent-Free HPLC

Determination of Remdesivir in Substances and Pharmaceutical Dosage Forms. Separations 2021, 8, 243. https://doi.org/10.3390/ separations 8120243

Academic Editor: Peter Mikuš

Received: 25 November 2021 Accepted: 10 December 2021 Published: 12 December 2021

Publisher's Note: MDPI stays neutral with regard to jurisdictional claims in published maps and institutional affiliations.

Copyright: (c) 2021 by the authors. Licensee MDPI, Basel, Switzerland. This article is an open access article distributed under the terms and conditions of the Creative Commons Attribution (CC BY) license (https:/ / creativecommons.org/licenses/by/ $4.0 /)$.

Abstract: A green liquid chromatographic method is considered in this work to minimize the environmental impact of waste solvents. One important principle is to replace or eliminate the use of hazardous organic solvents. Organic impurities in any active pharmaceutical ingredient could arise either during the process of its synthesis, or as degradation products developed throughout the shelflife. Remdesivir (RDS) is an antiviral drug, approved by the US Food and Drug Adminstration (-FDA), to treat SARS-Cov-2 virus during its pandemic crisis. We studied the stability of remdesivir against several degradation pathways using the organic solvent-free liquid chromatographic technique. Separation was performed on RP-C18 stationary phase using mixed-micellar mobile phase composed of a mixture of $0.025 \mathrm{M}$ Brij-35, 0.1 M sodium lauryl sulfate (SLS), and 0.02 M disodium hydrogen phosphate, adjusted to $\mathrm{pH}$ 6.0. The mobile phase flow rate was $1 \mathrm{~mL} \mathrm{~min}^{-1}$, and detection was carried out at a wavelength of $244 \mathrm{~nm}$. We profiled the impurities that originated in mild to drastic degradation conditions. The method was then validated according to International Conference of Harmonization (ICH) guidelines within a linearity range of $5-100 \mu \mathrm{g} \mathrm{mL}^{-1}$ and applied successfully for the determination of the drug in its marketed dosage form. A brief comparison was established with reported chromatographic methods, including a greenness assessment on two new metrics (GAPI and AGREE). This study is the first to be reported as eco-friendly, solvent-free, and stability indicating LC methodology for RDS determination and impurity profiling.

Keywords: remdesivir; COVID-19; mixed-micellar liquid chromatography; stability indicating method; green chromatography

\section{Introduction}

In December 2019, COVID-19 was discovered; since then, a pandemic infection has spread all over the world, causing patients pneumonia and acute respiratory distress syndrome that potentially progresses to death [1]. The causative organism was discovered to be SARS-Cov-2 virus, for which scientists have not yet discovered a specified regimen. Since the process of discovery, development and evaluation of any new active pharmaceutical ingredient (API) is tedious and requires a long time for safety and clinical profiling, older, clinically profiled antivirals were extensively tested against the new causative virus. Among these molecules, remdesivir (RDS) emerged as a promising active nucleus against the virus $[1,2]$. 
Remdesivir (structure depicted in Figure 1) is an adenosine nucleotide analogue that is activated in vivo into an active viral RNA polymerase inhibitor. During the Ebola virus outbreak (2014-2016), RDS was discovered and developed against Ebola virus. Although RDS by then had reached phase III of its clinical trials, it was over-performed by monoclonal antibodies against Ebola [3]. RDS showed increased intracellular concentration of its active triphosphate metabolite after single-dose administration, as well as inhibition of viral RNA polymerase that led to shortened recovery times and decreased mortality rates [4]. Therefore, RDS was recently approved by the US FDA and Japan for the treatment of severe COVID-19 cases [4], and since then it has been extensively formulated and produced by several countries all over the world.

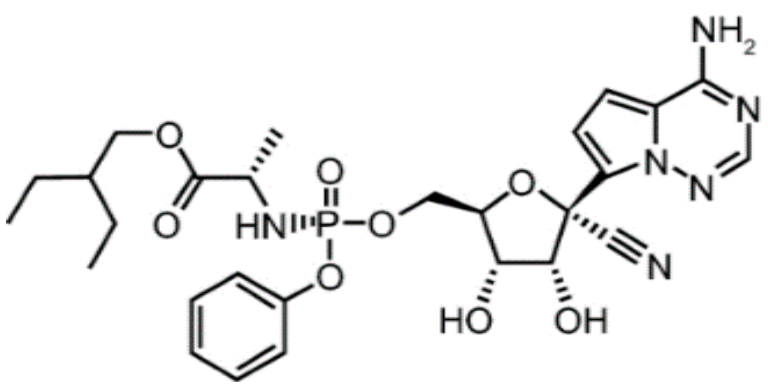

Figure 1. Chemical structure of RDS.

The process of quality control (QC) of any API in its crude raw powder form, as well as during several steps of its formulation, is crucial, in order to maintain good manufacturing practices (GMP). Pharmaceutical QC laboratories profile APIs for assessing the presence any organic impurities. These organic impurities can originate either during the synthesis process of the API, as degradation molecules during transport, storage, and manufacturing, or even during the product's shelf-life. An individual API product batch can be tested tens of times from its birth until expiry. This is how millions of analyses are performed daily in research and QC laboratories.

Meanwhile, the ecological impact of analytical methodologies must be controlled in order to decrease their environmental hazards. Ongoing greener in chromatography, reversed phase liquid chromatography (RPLC) is the best choice since it requires significantly fewer organic solvents than other stationary phases [5]. Organic solvents are used by chromatographers in RPLC to promote the analytes' elution and to improve their peak shape. However, given that each conventional LC system can generate around $0.5 \mathrm{~L}$ of organic waste daily [6], other techniques needed to be developed to decrease the dependence on these organic solvents, which are difficult both to produce and to dispose. Among the developed techniques, mixed-micellar mobile phases demonstrated adequate performance at replacing hazardous organic solvents $[7,8]$. The combination of the non-ionic polyoxyethylene surfactant (Brij-35) and the anionic sodium lauryl sulfate (SLS) surfactant improved the elution power in RP stationary phases without the loss of their separation efficiency [9]. This technique involves much lower cost, toxicity and environmental harm; moreover, it offers unique selectivity and power of solubilization. These advantages encourage economic pharmaceutical corporations to utilize methodologies related to such techniques that avoid the disadvantages of expensive and ecologically harmful solvents in their routine inspections.

A literature review revealed that only a small number of methodologies were validated for the determination of RDS. Most methods were based on HPLC or ultrahigh performance liquid chromatography (UHPLC) coupled with MS/MS detection [10-15]. Some detailed data regarding these cited references are discussed and compared for their advantages and disadvantages in the Discussion section. Except for one reported method [13], other methods validated a gradient LC technique. Formic acid, sodium formate and ammonium acetate were the main buffers of the mobile phases. The flow rates of the reported methodologies ranged from $0.4-0.6 \mathrm{~mL} \mathrm{~min}^{-1}$, with a run time range of 4.0-10.0 min per 
run. The method described in [11] used anion exchange stationary phase, while the other reported methods used an RP-C18 column as stationary phase. All the reported techniques utilized organic solvents, such as acetonitrile $(\mathrm{ACN})$ and methanol $(\mathrm{MeOH})$, to improve elution and chromatographic efficiencies. No solvent-free HPLC method was reported for the determination of RDS. Moreover, all the reported methods until now quantified the drug in plasma or body tissues using HPLC or UHPLC coupled with an MS/MS detector. Although UHPLC-MS/MS utilizes low amounts of reagents, its high maintenance cost and short column life are worrying issues for low-budget laboratories. Therefore, as expensive tools, they are not readily present in most of QC laboratories [6]. Another electrochemical for the determination of RDS was also reported [16].

The aim of this research article is to validate a simple, conventional and green LC method for the determination of RDS in its pure form, as well as in pharmaceutical product forms. The method is the first to be reported as stability indicating method that can profile existing organic degradation impurities. The method is sustainable since it is solvent free and was assessed for greenness against recent metrics and compared to previously reported analytical methodologies in order to prove its efficiency and desirable ecological safety.

\section{Materials and Methods}

\subsection{Materials}

All the reagents used were of analytical grades. The Brij-L23 was purchased from Alfa Aesar GmbH, Tewksbury, MA, USA. The phosphoric acid, SLS, disodium hydrogen phosphate and methanol were purchased from Merck, Darmstadt, Germany. The de-ionized water was freshly produced in-house (using a Millipore water system for purification).

The RDS was kindly supplied by EIPICo., tenth of Ramadan city, Egypt. The pharmaceutical dosage form Remdesivir-Rameda ${ }^{\circledR}$ I.V. infusion (lot. No. 203526, 100 mg RDS per $20 \mathrm{~mL}$ vial), and Betacyclodextrin sulfobutyl ether sodium (BCD-SE) were kindly supplied by Rameda, October, Egypt.

\subsection{Instrumentation}

The study was performed on an Agilent-1200 chromatographic system (Rocklin, CA, USA) equipped with a quaternary pump, an auto-sampler, a PDA detector, and a mobile phase degasser (models G1311A, G1329B, G1315B and G1322A, respectively). A MettlerToledo meter, SevenCompact ${ }^{\circledR}$ model S210 (Columbus, MN, USA), was utilized for $\mathrm{pH}$ adjustment. A Core-shell RP-C18 column Kinetix ${ }^{\circledR}(5 \mu \mathrm{m}, 150 \times 4.6 \mathrm{~mm})$ was purchased from Phenomenex, CA, USA.

\subsection{Chromatographic Separation Conditions}

The mobile phase was prepared by dissolving $0.025 \mathrm{M}$ Brij, $0.1 \mathrm{M}$ SLS and $0.02 \mathrm{M}$ of disodium hydrogen phosphate in $1 \mathrm{~L}$ of de-ionized water and the $\mathrm{pH}$ was adjusted to 6.0 using dilute phosphoric acid. The mobile phase was filtered, degassed and eluted isocratically on a chromatographic column, at a flow rate of $1 \mathrm{~mL} \mathrm{~min}{ }^{-1}$ for 9 min during the method validation. The detection wavelength was adjusted to $244 \mathrm{~nm}$.

To enhance the sustainability of the analytical procedure, the mobile phase was recycled in between the chromatographic runs. To maintain the column efficiency and remove all the surfactants that were adsorbed on the stationary phase, the system needed to be purged for fifteen minutes using a regenerating mobile phase composed of water, $\mathrm{MeOH}(50: 50, v / v)$, at the end of each working day.

\subsection{Preparation of Stock Solutions, Standard Solutions and Pharmaceutical Dosage Form}

The RDS stock solution was prepared by dissolving $50.0 \mathrm{mg}$ of pure powder in $10 \mathrm{~mL}$ of $\mathrm{MeOH}$ with sonication for $2 \mathrm{~min}$. The volume was then increased to $50 \mathrm{~mL}$ using the mobile phase. The stock solution was stored in a refrigerator (at $2-8{ }^{\circ} \mathrm{C}$ ) in amber glass bottles and was stable for more than 2 weeks. 
The linearity was established by diluting the stock solution with the mobile phase to obtain six standard solutions at $\left(5,20,40,60,80\right.$ and $\left.100 \mu \mathrm{g} \mathrm{mL}^{-1}\right)$. Quality control (QC) standards were prepared by spiking the RDS stock solution into a placebo solution containing $1 \mathrm{mg} \mathrm{mL}^{-1}$ of (BCD-SE), adjusted to $\mathrm{pH} 4.0$ using phosphoric acid in order to simulate the drug delivery system of Remdesivir-Rameda ${ }^{\circledR}$ I.V. infusion, to obtain four QC standards at $\left(10,25,50\right.$ and $\left.75 \mu \mathrm{g} \mathrm{mL}{ }^{-1}\right)$.

The validated method was applied for the determination of RDS in its marketed pharmaceutical dosage form. The assay was performed through the direct dilution of the Remdesivir-Rameda ${ }^{\circledR}$ I.V. infusion using the mobile phase to concentration $\left(50.0 \mu \mathrm{g} \mathrm{mL}^{-1}\right)$.

\subsection{Drug Forced Degradation}

In the proposed study, the stress protocol was chosen to effect acid/base hydrolysis, oxidative and thermal degradation to RDS [17]. The RDS was prepared at a concentration of $1 \mathrm{mg} \mathrm{mL} \mathrm{mL}^{-1}$ and was then subjected to degradation according the following protocol. Alkaline hydrolysis was performed in $0.1 \mathrm{~N} \mathrm{NaOH}$ at $\left(25^{\circ} \mathrm{C} / 0.5 \mathrm{~h}\right),\left(25^{\circ} \mathrm{C} / 3 \mathrm{~h}\right)$ and $\left(45^{\circ} \mathrm{C} / 1 \mathrm{~h}\right)$. Acidic hydrolysis was performed in $0.1 \mathrm{~N} \mathrm{HCl}$ at $40{ }^{\circ} \mathrm{C}$ and $50{ }^{\circ} \mathrm{C}$ in a calibrated water bath for $1 \mathrm{~h}$, respectively. Oxidative degradation was carried out in hydrogen peroxide $4.5 \%$ at $40^{\circ} \mathrm{C}$ and $50^{\circ} \mathrm{C}$ for $1 \mathrm{~h}$, respectively. Photolytic degradation was done by exposing the drug solution to Ultra-violet (UV) lamp at $365 \mathrm{~nm}$ for 1 day. Finally, after acid/base hydrolysis, the process must be stopped by neutralizing acidic/basic solutions. The oxidative degradation was stopped by adding sodium persulfate powder to remove excess remaining hydrogen peroxide.

\section{Results}

\subsection{Analytical Method Validation}

The developed method was validated according to ICH guidelines [18]. The linearity was established using six linearity standards across the specified range. The standards were injected in triplicates and the average corresponding areas under the curve were plotted against their corresponding drug concentrations. Table 1 outlines the retention time and regression equation statistics.

Table 1. Linearity and regression results for determination of RDS using the proposed LC method.

\begin{tabular}{cc}
\hline Parameter & Result \\
\hline Retention time $($ min \pm SD) & $8.5 \pm 0.4$ \\
Number of theoretical plates & $9550 \mathrm{~m}^{-1}$ \\
Symmetry factor & 0.83 \\
Linearity range $\left(\mu \mathrm{g} \mathrm{mL}^{-1}\right)$ & $5.0-100.0$ \\
Linearity equation & $\mathrm{Y}=64.4 \mathrm{X}-42.5$ \\
Correlation coefficient $(r)$ & 0.999 \\
LOD $(\mathrm{S} / \mathrm{N}$ ratio $=3)$ & $0.5 \mu \mathrm{g} \mathrm{mL}^{-1}$ \\
LOQ $(\mathrm{S} / \mathrm{N}$ ratio $=10)$ & $2.0 \mu \mathrm{g} \mathrm{mL}^{-1}$ \\
\hline
\end{tabular}

Specificity is the ability of the analytical method to determine the analyte in the presence of interferences. The absence of interferences from any present excipients is demonstrated by the chromatograms obtained from pure RDS and RDS Remdesivir-Rameda ${ }^{\circledR}$ in dosage form (Figure 2). Both RDS peaks were identical and indicated that no interferences from the excipients were found. 

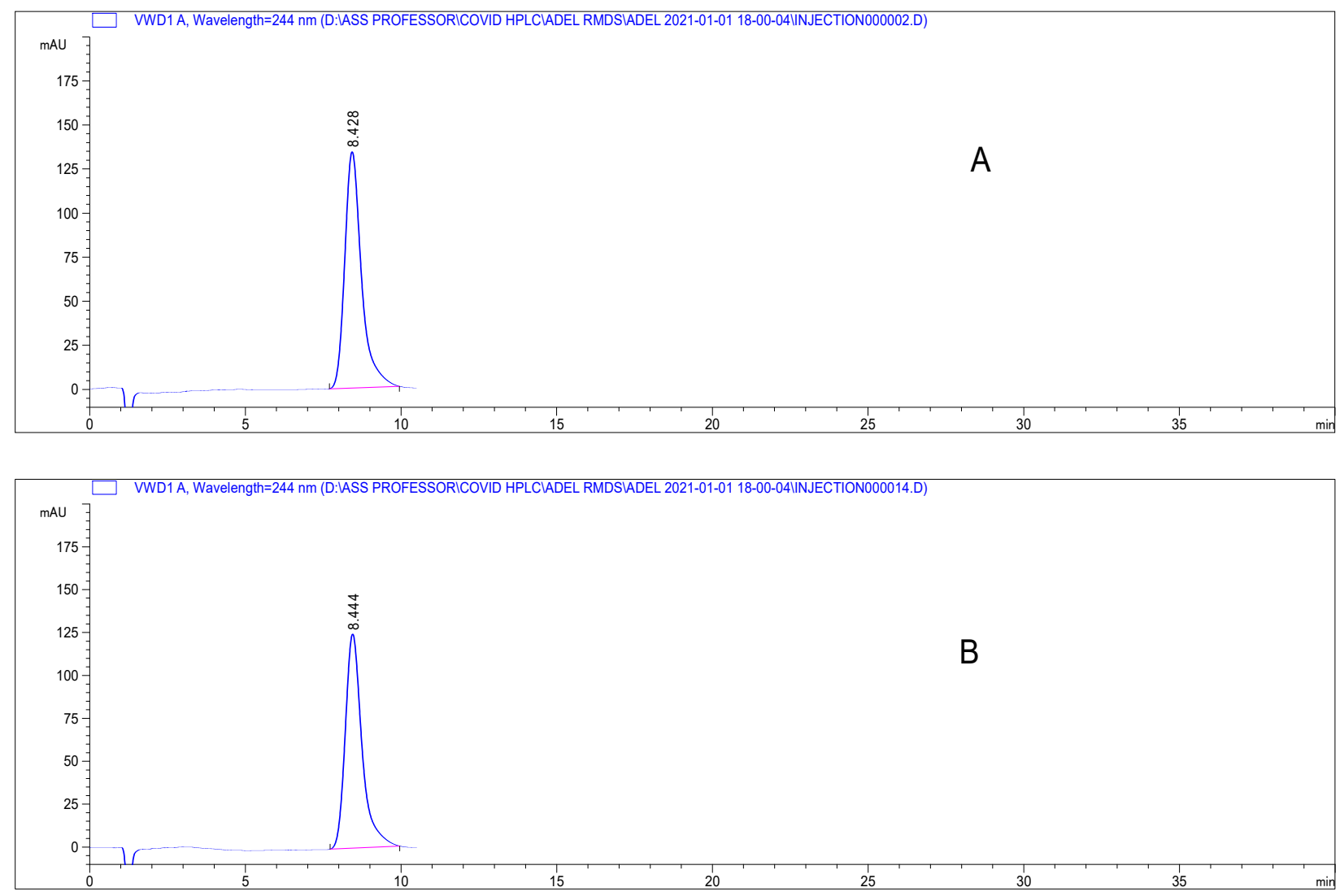

Figure 2. Chromatograms presenting elution of RDS (A) pure form $\left(80 \mu \mathrm{g} \mathrm{mL}^{-1}\right)$, (B) diluted Remdesivir-Rameda ${ }^{\circledR} \mathrm{IV}$ infusion under the proposed chromatographic conditions.

The system's suitability was evaluated using the proposed mobile phase in the absence of organic solvents, which are important for the enhancement of peak shape. The parameters tested included repeatability of retention time, column efficiency in terms of number of theoretical plates and peak symmetry. The results (Table 1) for the higher-concentration linearity standard $\left(80 \mu \mathrm{g} \mathrm{mL}^{-1}\right)$ established the system's adequacy for the analysis using the solvent-free mobile phase without a considerable loss of efficiency.

The limits of detection (LOD) and quantification (LOQ) were calculated based on signal-to-noise ratios (Table 1), where descending concentrations of RDS were injected and ratios were considered. The LOD and LOQ were determined using drug concentrations that produced signal-to-noise ratios 3 and 10, respectively.

The accuracy of the developed method was proven by injecting four QC standards in triplicates and calculating the percentage recoveries obtained from the regression equation. Table 2 presents the accuracy results, which proved the close agreement between the expected and true values.

Table 2. Accuracy and precision results for determination of RDS using the proposed method.

\begin{tabular}{cccc}
\hline $\begin{array}{c}\text { Concentration } \\
\left(\mu \mathbf{g ~ m L}^{-\mathbf{1}}\right)\end{array}$ & Accuracy * & Inter-Day Precision * & Intra-Day Precision * \\
\hline $\mathbf{1 0 . 0}$ & $102.6 \pm 0.4$ & $101.8 \pm 1.4$ & $101.3 \pm 1.7$ \\
$\mathbf{2 5 . 0}$ & $100.3 \pm 1.7$ & $100.2 \pm 0.9$ & $100.1 \pm 0.6$ \\
$\mathbf{5 0 . 0}$ & $97.8 \pm 0.6$ & $98.4 \pm 1.3$ & $98.5 \pm 1.1$ \\
$\mathbf{7 5 . 0}$ & $101.9 \pm 2.4$ & $102.5 \pm 1.4$ & $101.6 \pm 1.9$ \\
\hline
\end{tabular}

* Results: \%Recovery \pm standard deviation, Average of triplicate injections per quality control concentration $(n=3)$. 
The precision was tested by evaluating the repeatability and intermediate precision. The repeatability of the triplicate injections of linearity standards under the same operating conditions resulted in low relative standard deviation (RSD). The intermediate precision was tested using the four QC standards, which were injected at three different times during the same day (Intra-day) and on three different days (Inter-day). Table 2 presents the intermediate precision, where the standard deviations of the results prove the agreement between the different measurements.

\subsection{Stability Indicating Capability of the Proposed Method}

In order to specify the stability-indicating capability of any analytical methodology, forced degradation must be performed for the analyte under conditions more drastic than normal or even accelerated conditions [17]. Drug degradation became an essential step for regulatory approval during the development of new API formulas. Although regulatory documents do not specify exact details for degradation studies, stress conditions must be chosen to simulate possible pathways to decompose APIs during manufacture, transport, storage or shelf-life [19].

Alkaline hydrolysis exerted the most drastic effect on the RDS nucleus (Supplementary Material Figure S1), where complete hydrolysis occurred. Even at the mildest alkaline degradation $\left(0.1 \mathrm{~N} \mathrm{NaOH}, 25^{\circ} \mathrm{C} / 0.5 \mathrm{~h}\right.$ ), RDS degradation was up to nearly $95 \%$ (Figure 3 ). The RDS nucleus withstood the acidic degradation more than the peroxide oxidation, as demonstrated in the Supplementary Material (Figure S1). Photolytic degradation did not produce a significant change on the RDS nucleus. In all cases, none of the formed impurities interfered with the RDS peak (Supplementary Material Figure S1).

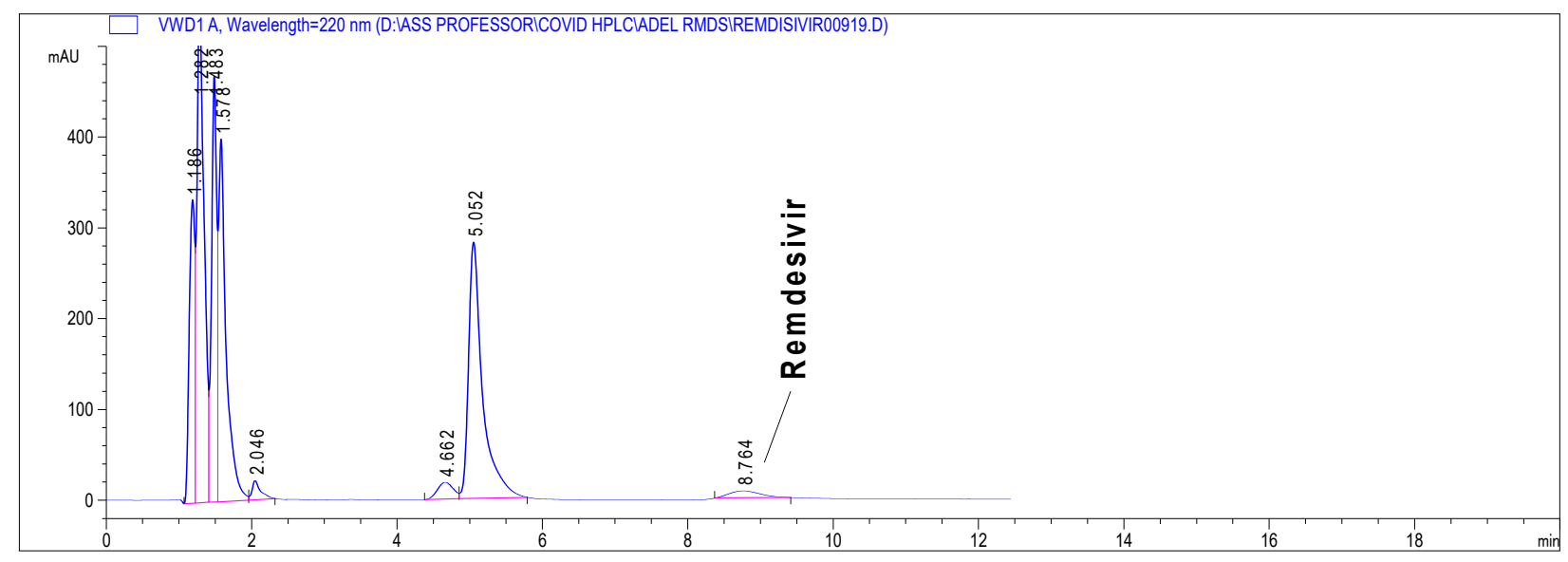

Figure 3. Chromatogram presenting stress degradation results of RDS in $0.1 \mathrm{~N} \mathrm{NqOH}, 25^{\circ} \mathrm{C} / 0.5 \mathrm{~h}$ under the proposed chromatographic conditions.

\subsection{Method Application}

The validated method was applied for the assay of RSD in its marketed dosage form (Remdesivir-Rameda ${ }^{\circledR}$ ). The IV solution was diluted and injected within the working range of the method in triplicates. The concentrations were calculated using the calibration equation. The results were then compared to those obtained by a reference method obtained from a dosage form formulator EIPICo., tenth of Ramadan city, Egypt. The formulator describes a HPLC method for its determination using mobile phase consisting of $0.1 \%$ phosphoric acid in water: methanol $(35: 65, v / v)$ eluting at flow rate $1 \mathrm{~mL} \mathrm{~min}^{-1}$ on a C18-RP column and a detection wavelength of $237 \mathrm{~nm}$. Table 3 presents the obtained results and their evaluation on the student $t$-test and F-test. The results prove the absence of any significant differences between the reported and validated methods. 
Table 3. Application of the proposed method for the determination of RDS in Remdesivir-Rameda ${ }^{\circledR}$.

\begin{tabular}{cccc}
\hline Proposed Method ${ }^{*}$ & Reference Method $^{*}$ & $\boldsymbol{t}$-Test & F-Test \\
\hline $100.8 \pm 1.4$ & $101.4 \pm 0.8$ & $0.531(2.776)$ & $3.213(19)$ \\
\hline${ }^{*}$ Results $=\%$ Recovery \pm relative standard deviation, $(n=3)$. & &
\end{tabular}

\subsection{Comparison and Evaluation to Previously Reported Methods}

As mentioned in the Introduction section, according to our knowledge, only a small number of chromatographic methods were reported for the determination of RDS, mainly in plasma, which were based mainly on UHPLC coupled with MS/MS detection. UHPLC is an expensive tool that cannot be used economically in routine $\mathrm{QC}$ procedures due to its high maintenance cost and short column life-time [20]. Table 4 presents a thorough comparison between the proposed method and five other reported methodologies. The present study is the only one to depend on a conventional LC, which is widely available in most pharmaceutical QC laboratories. All other methodologies are related to UHPLC, of which one reported method presented 2D UHPLC separation [14]. Although UHPLC systems are the most efficient separation tools, utilizing only a small amount of reagents and presenting higher sensitivities, they feature some well-known drawbacks. The low reproducibility they offer, their short column life-time and the high cost of their maintenance discourage their use in economical pharmaceutical facilities for routine daily QC tasks [20]. This study is the only solvent-free tool, in which the compared methodologies mostly use acetonitrile as organic solvent, except one method which uses a methanol-based mobile phase ready kit [14]. ACN features a unique selectivity; however, several reports refer to its high toxicity and environmental hazardousness, added to its expensive production and tedious disposal [21].

Table 4. Comparison of the proposed analytical methods to chosen reported methodologies.

\begin{tabular}{|c|c|c|c|c|c|c|}
\hline & Proposed Method & $\begin{array}{c}\text { Reported Method } \\
[11]]\end{array}$ & $\begin{array}{l}\text { Reported Method } \\
\text { [12] }\end{array}$ & $\begin{array}{l}\text { Reported Method } \\
{[14]}\end{array}$ & $\begin{array}{c}\text { Reported Method } \\
{[13]}\end{array}$ & $\begin{array}{c}\text { Reported Method } \\
{[15]}\end{array}$ \\
\hline Technique & HPLC-UV & UHPLC-MS/MS & HPLC-MS/MS & UHPLC-MS/MS & UHPLC-MS/MS & UHPLC-MS/MS \\
\hline $\begin{array}{c}\text { Matrix; } \\
\text { Application }\end{array}$ & $\begin{array}{l}\text { Bulk powder; } \\
\text { Drug QC }\end{array}$ & $\begin{array}{l}\text { Mouse tissue, } \\
\text { Clinical studies }\end{array}$ & $\begin{array}{c}\text { Plasma; Clinical } \\
\text { studies }\end{array}$ & $\begin{array}{c}\text { Plasma; Clinical } \\
\text { studies }\end{array}$ & $\begin{array}{c}\text { Plasma; Clinical } \\
\text { studies }\end{array}$ & $\begin{array}{c}\text { Plasma; Clinical } \\
\text { studies }\end{array}$ \\
\hline Linearity range & 5-100 $\mu \mathrm{g} \mathrm{mL}^{-1}$ & $6.0-60,260 \mathrm{ng} \mathrm{mL}^{-1}$ & $1-5000 \mathrm{ng} \mathrm{mL}^{-1}$ & $1-1000 \mathrm{ng} \mathrm{mL}^{-1}$ & $1-5000 \mathrm{ng} \mathrm{mL}^{-1}$ & $85-5450 \mathrm{ng} \mathrm{mL}^{-1}$ \\
\hline LOD & $500 \mathrm{ng} \mathrm{mL}^{-1}$ & $0.3 \mathrm{ng} \mathrm{mL}^{-1}$ & $0.3 \mathrm{ng} \mathrm{mL}^{-1}$ & Not available & $0.24 \mathrm{ng} \mathrm{mL}^{-1}$ & Not available \\
\hline LOQ & $2000 \mathrm{ng} \mathrm{mL}^{-1}$ & $1.0 \mathrm{ng} \mathrm{mL}^{-1}$ & $1.0 \mathrm{ng} \mathrm{mL}^{-1}$ & Not available & $0.98 \mathrm{ng} \mathrm{mL}^{-1}$ & $4.0 \mathrm{ng} \mathrm{mL}^{-1}$ \\
\hline Organic phase & Nil & $\mathrm{ACN}$ & $\mathrm{ACN}$ & $\mathrm{ACN}$ & $\mathrm{ACN}$ & Methanol-based \\
\hline Run time (min) & 9.0 & 6.5 & 5.0 & 4.0 & 10.0 & 5.0 \\
\hline Column & $\begin{array}{c}\mathrm{C} 18(5 \mu \mathrm{m}, 150 \times \\
4.6 \mathrm{~mm})\end{array}$ & $\begin{array}{c}\text { Anion exchange } \\
\text { BioBasic AX column } \\
(2.1 \mu \mathrm{m}, 50 \times \\
4.6 \mathrm{~mm})\end{array}$ & $\begin{array}{c}\mathrm{C} 18(2.6 \mu \mathrm{m}, 100 \\
\times 2.1 \mathrm{~mm})\end{array}$ & $\begin{array}{c}\mathrm{C} 18(1.8 \mu \mathrm{m}, 50 \times \\
2.1 \mathrm{~mm})\end{array}$ & $\begin{array}{c}\mathrm{C} 18(3 \mu \mathrm{m}, 150 \times \\
4.6 \mathrm{~mm})\end{array}$ & $\begin{array}{c}\text { Separation on C18 } \\
\text { (MassTox }{ }^{\circledR} \text { TDM } \\
\text { column) after solid } \\
\text { phase extraction }\end{array}$ \\
\hline \multirow{3}{*}{ Mobile phase } & Isocratic; & Gradient; & Gradient; & Gradient; & Isocratic; & Gradient; \\
\hline & $\begin{array}{l}\text { Mixed mode of } \\
\text { Brij and SLS. }\end{array}$ & $\begin{array}{l}\text { Ammonium acetate } \\
\text { buffer and ACN }\end{array}$ & $\begin{array}{l}\text { Sodium formate } \\
\text { buffer and ACN }\end{array}$ & $\begin{array}{l}0.05 \% \text { formic acid } \\
\text { and ACN }\end{array}$ & $\begin{array}{l}0.05 \% \text { formic acid: } \\
\text { ACN (52:48) }\end{array}$ & $\begin{array}{c}\text { MassTox }^{\circledR} \text { series A } \\
\text { mobile phase }\end{array}$ \\
\hline & Flow; $1 \mathrm{~mL} \mathrm{~min}{ }^{-1}$ & 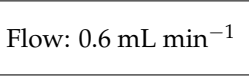 & $\begin{array}{l}\text { Flow; } 0.5 \mathrm{~mL} \\
\mathrm{~min}^{-1}\end{array}$ & $\begin{array}{l}\text { Flow; } 0.4 \mathrm{~mL} \\
\min ^{-1}\end{array}$ & $\begin{array}{l}\text { Flow; } 0.5 \mathrm{~mL} \\
\min ^{-1}\end{array}$ & $\begin{array}{l}\text { Flow; } 0.6 \mathrm{~mL} \\
\min ^{-1}\end{array}$ \\
\hline \multicolumn{7}{|l|}{$\begin{array}{c}\text { GAPI } \\
\text { assessment }\end{array}$} \\
\hline $\begin{array}{l}\text { AGREE } \\
\text { assessment }\end{array}$ & & & & & & \\
\hline
\end{tabular}


The comparison presents an assessment of the reported methods on two recent assessment metrics: the Green Analytical Procedure Index (GAPI) [22] and AGREE [23]. GAPI is a color-coded index that features a figure composed of 15 pentagrams, each representing a step in the analytical procedure. It assesses the analytical method using three colors; red indicates high environmental impact, yellow indicates moderate and green indicates a low hazardous effect. Another recent metric was reported, AGREE [23], which is based on Green Analytical Chemistry (GAC) principles. AGREE features a clock-shaped figure. The perimeter of the clock is divided into 12 sectors, each representing one GAC principle. The same color coding is preserved for both GAPI and AGREE. However, AGREE introduces a numerical evaluation for the assessed method in the core of its graph, ranging from (0.0-1.0). As demonstrated in Table 4, the proposed method has the greenest impact on both GAPI and AGREE for several reasons. Firstly, it is the only reported solvent-free method. Furthermore, this study uses biodegradable mobile phase micellar constituents. Since the previously reported methods were applied in biological tissues, they require extraction steps that range from simple protein precipitation to complex advanced extraction. The only red zones in the GAPI pictogram for the proposed study (also present in other reported methods) correspond to the off-line sampling and positioning of analytical instrumentation in QC laboratories, which is a regulatory requirement in pharmaceutical establishments.

In the assessment of the GAPI and AGREE metrics, GAPI failed to distinguish between four of the five comparison references. These methods were based on UHPLC-MS/MS, using ACN as organic modifier; since they are UHPLC, they utilized and produced less than $10 \mathrm{~mL}$ of organic solvents and waste, respectively. On the other hand, AGREE was able to differentiate between these methods based on the consideration of some other factors. AGREE considers the total run time and procedure through the output expressed by the number of runs per working hour. Along with presenting a numerical estimating figure for assessment, AGREE can demonstrate its superiority. However, AGREE features an important drawback in that it does not differentiate between reagents and solvents to the same extent as GAPI, which uses the National Fire Protection Association (NFPA)'s health and safety hazard codes for used reagents and solvents.

The proposed method offers a low ecological impact on both metrics, together with cost-effectiveness, robust design and high predictability. It is therefore recommended to be applied in the quality control quantification of any combination of the tested analytes as a green alternative to any reported methodology.

\section{Conclusions}

A new, simple, fast and economical method was developed and validated for the determination of remdesivir, one of the currently used medications for the treatment of COVID-19 infections. The developed method can profile the drug in the presence of its stress degradation impurities without interferences. Moreover, the proposed method is green and cost-effective, so it can be applied for the routine quality control analyses of remdesivir with high predictability. The method was found to have the lowest ecological impact, as assessed on both GAPI and AGREE greenness metrics.

Supplementary Materials: The following are available online at https:/ / www.mdpi.com/article/10 $.3390 /$ separations $8120243 / \mathrm{s} 1$, Figure S1. Chromatograms showing degradation of RDS in (A) $0.1 \mathrm{~N}$ $\mathrm{NaOH}, 25^{\circ} \mathrm{C} / 3 \mathrm{~h}(\mathrm{~B}) 0.1 \mathrm{~N} \mathrm{HCl}, 40{ }^{\circ} \mathrm{C} / 1 \mathrm{~h}$, (C) $4.5 \%$ hydrogen peroxide, $50{ }^{\circ} \mathrm{C} / 1 \mathrm{~h}$, (D) Photolytic degradation; under the proposed chromatographic conditions

Author Contributions: Conceptualization, A.E.I. and S.E.D.; methodology, E.M.A. and R.A.S.; validation, R.A.S. and A.E.I.; formal analysis, A.E.I. and R.A.S.; investigation, A.E.I. and S.E.D.; resources, A.E.I. and S.E.D.; writing-original draft preparation, A.E.I. and R.A.S.; writing-review and editing, S.E.D. and A.A.-H.; visualization, A.E.I. and E.M.A.; supervision, S.E.D.; project administration, S.E.D. All authors have read and agreed to the published version of the manuscript.

Funding: This research received no external funding to declare. 
Conflicts of Interest: The authors declare that there is no conflict of interest. This article does not contain any studies with animals or human volunteers.

\section{References}

1. Scavone, C.; Brusco, S.; Bertini, M.; Sportiello, L.; Rafaniello, C.; Zoccoli, A.; Berrino, L.; Racagni, G.; Rossi, F.; Capuano, A. Current pharmacological treatments for COVID-19: What's next? Br. J. Pharmacol. 2020, 177, 4813-4824. [CrossRef] [PubMed]

2. Williamson, B.N.; Feldmann, F.; Schwarz, B.; Meade-White, K.; Porter, D.P.; Schulz, J.; Van Doremalen, N.; Leighton, I.; Yinda, C.K.; Pérez-Pérez, L. Clinical benefit of remdesivir in rhesus macaques infected with SARS-CoV-2. Nature 2020, 585, 273-276. [CrossRef] [PubMed]

3. Lamb, Y.N. Remdesivir: First Approval. Drugs 2020, 80, 1355-1363. [CrossRef] [PubMed]

4. Humeniuk, R.; Mathias, A.; Cao, H.; Osinusi, A.; Shen, G.; Chng, E.; Ling, J.; Vu, A.; German, P. Safety, tolerability, and pharmacokinetics of remdesivir, an antiviral for treatment of COVID-19, in healthy subjects. Clin. Transl. Sci. 2020, 13, 896-906. [CrossRef] [PubMed]

5. Aly, A.A.; Górecki, T. Green Analytical Chemistry: Past, Present and Perspectives; Płotka-Wasylka, J., Namieśnik, J., Eds.; Springer: Singapore, 2019; pp. 241-298.

6. Sayed, R.A.; Ibrahim, A.E.; Sharaf, Y.A. Chemometry-assisted UV-spectrophotmetric methods for the simultaneous determination of paritaprevir, ritonavir, and ombitasvir in their combined tablet dosage forms: A comparative study. J. Chemom. 2021, 35, e3339. [CrossRef]

7. Duan, X.; Liu, X.; Dong, Y.; Duan, T.; Zhang, J.; He, S.; Yang, F.; Dong, Y. A Mixed Micellar Liquid Chromatography with Direct Injection for Rapid Analysis of Eight Sulfonamides in Milk. Food Anal. Methods 2020, 13, 1148-1158. [CrossRef]

8. Alwera, V.; Sehlangia, S.; Alwera, S. Micellar liquid chromatographic green enantioseparation of racemic amino alcohols and determination of elution order. Biomed. Chromatogr. 2020, 34, e4954. [CrossRef] [PubMed]

9. Ibrahim, A.E.; Elmansi, H.; Belal, F. Solvent-free mixed micellar mobile phases; an advanced green chemistry approach for reversed phase HPLC determination of some antihypertensive drugs. J. Sep. Sci. 2020, 43, 3224-3232. [CrossRef] [PubMed]

10. Hu, W.; Chang, L.; Ke, C.; Xie, Y.; Shen, J.; Tan, B.; Liu, J. Challenges and stepwise fit-for-purpose optimization for bioanalyses of remdesivir metabolites nucleotide monophosphate and triphosphate in mouse tissues using LC-MS/MS. J. Pharm. Biomed. Anal. 2021, 194, 113806. [CrossRef] [PubMed]

11. Alvarez, J.-C.; Moine, P.; Etting, I.; Annane, D.; Larabi, I.A. Quantification of plasma remdesivir and its metabolite GS-441524 using liquid chromatography coupled to tandem mass spectrometry. Application to a Covid-19 treated patient. Clin. Chem. Lab. Med. (CCLM) 2020, 58, 1461-1468. [CrossRef] [PubMed]

12. Pasupuleti, R.R.; Tsai, P.-C.; Ponnusamy, V.K.; Pugazhendhi, A. Rapid determination of remdesivir (SARS-CoV-2 drug) in human plasma for therapeutic drug monitoring in COVID-19-Patients. Process Biochem. 2021, 102, 150-156. [CrossRef] [PubMed]

13. Avataneo, V.; de Nicolò, A.; Cusato, J.; Antonucci, M.; Manca, A.; Palermiti, A.; Waitt, C.; Walimbwa, S.; Lamorde, M.; di Perri, G.; et al. Development and validation of a UHPLC-MS/MS method for quantification of the prodrug remdesivir and its metabolite GS-441524: A tool for clinical pharmacokinetics of SARS-CoV-2/COVID-19 and Ebola virus disease. J. Antimicrob. Chemother. 2020, 75, 1772-1777. [CrossRef] [PubMed]

14. Habler, K.; Brügel, M.; Teupser, D.; Liebchen, U.; Scharf, C.; Schönermarck, U.; Vogeser, M.; Paal, M. Simultaneous quantification of seven repurposed COVID-19 drugs remdesivir (plus metabolite GS-441524), chloroquine, hydroxychloroquine, lopinavir, ritonavir, favipiravir and azithromycin by a two-dimensional isotope dilution LC-MS/MS method in human serum. J. Pharm. Biomed. Anal. 2021, 196, 113935. [CrossRef] [PubMed]

15. Xiao, D.; John Ling, K.H.; Tarnowski, T.; Humeniuk, R.; German, P.; Mathias, A.; Chu, J.; Chen, Y.-S.; van Ingen, E. Validation of LC-MS/MS methods for determination of remdesivir and its metabolites GS-441524 and GS-704277 in acidified human plasma and their application in COVID-19 related clinical studies. Anal. Biochem. 2021, 617, 114118. [CrossRef] [PubMed]

16. Tkach, V.V.; Kushnir, M.; de Oliveira, S.C.; Ivanushko, J.; Velyka, A.V.; Molodianu, A.F.; Yagodynets, P.I.; Kormosh, Z.O.; Vaz dos Reis, L.; Luganska, O.V. Theoretical Description for Anti-COVID-19 Drug Remdesivir Electrochemical Determination, Assisted by Squaraine Dye-Ag2O2 Composite. Biointerface Res. Appl. Chem. 2021, 11, 9201-9208.

17. Blessy, M.; Patel, R.D.; Prajapati, P.N.; Agrawal, Y.K. Development of forced degradation and stability indicating studies of drugs-A review. J. Pharm. Anal. 2014, 4, 159-165. [CrossRef] [PubMed]

18. Guideline. International Conference on Harmonization; Validation of Analytical Procedures, ICH Q2 (R1); ICH: Geneva, Switzerland, 2005; pp. 11-12.

19. Guideline. International Conference on Harmonisation of Technical Requirements for the Registration of Pharmaceuticals for Human Use; ICH: Geneva, Switzerland, 2003.

20. Taleuzzaman, M.; Ali, S.; Gilani, S.J.; Imam, S.S.; Hafeez, A. Ultra performance liquid chromatography (UPLC)-a review. Austin. J. Anal. Pharm. Chem. 2015, 2, 1056-1060.

21. Ibrahim, A.E.; Elmaaty, A.A.; El-Sayed, H.M. Determination of six drugs used for treatment of common cold by micellar liquid chromatography. Anal. Bioanal. Chem. 2021, 413, 5051-5065. [CrossRef] [PubMed]

22. Płotka-Wasylka, J. A new tool for the evaluation of the analytical procedure: Green Analytical Procedure Index. Talanta 2018, 181, 204-209. [CrossRef] [PubMed]

23. Pena-Pereira, F.; Wojnowski, W.; Tobiszewski, M. AGREE—Analytical GREEnness Metric Approach and Software. Anal. Chem. 2020, 92, 10076-10082. [CrossRef] [PubMed] 